\title{
Prevalence of temporomandibular dysfunction in children and adolescents
}

\author{
Prevalência de disfunção temporomandibular em crianças e adolescentes \\ Prevalencia de disfunción témporomandibular en niños y adolescentes
}

Marina Fernandes de Sena ${ }^{1}$, Késsia Suênia F. de Mesquita ${ }^{1}$, Fernanda Regina R. Santos ${ }^{1}$, Francisco Wanderley G. P. Silva ${ }^{1}$,

Kranya Victoria D. Serrano ${ }^{1}$

\section{ABSTRACT}

Objective: To review the prevalence of temporomandibular disorders (TMD) in children and adolescents, verifying the methodological variations.

Data sources: Research conducted in Medline, PubMed, Lilacs and BBO databases, including manuscripts (except reviews and case reports) published from 1990 to 2012. The descriptors were "temporomandibular joint syndrome", "temporomandibular joint dysfunction syndrome", "temporomandibular joint disorders", "prevalence studies", and "cross-sectional studies"; the words "dysfunction", "disorder", "temporomandibular", "children”, "adolescents", "prevalence", "frequency", and "transversal" were used.

Data synthesis: Seventeen articles were selected, and the TMD frequency varied from 16 to $68 \%$. Regarding the methodological criteria, only three articles (18\%) reported sample size determination, three (18\%) clearly described the sample selection process by stratified selection technique, and nine studies $(53 \%)$ carried out the calibration of the examiners. The diagnostic criteria used in the studies were: Helkimo index $(\mathrm{n}=2 ; 12 \%)$, Research Diagnostic Criteria for Temporomandibular Disorders (RDC/TMD) $(n=4 ; 24 \%)$, the jaw index $(n=1 ; 6 \%)$, clinical protocols $(n=10 ; 59 \%)$, and anamnestic questionnaires $(\mathrm{n}=6 ; 35 \%)$.

Conclusions: The TMD prevalence in children and adolescents varies in the literature. Appropriate and standardized methods are needed to identify, with greater validity,

Instituição: Universidade de São Paulo (USP), Ribeirão Preto, SP, Brasil

${ }^{1}$ Faculdade de Odontologia de Ribeirão Preto da USP, Ribeirão Preto, SP, Brasil the presence of TMD in this population, allowing a better understanding of the pathological aspects in order to address more effective preventive and therapeutic procedures.

Key-words: temporomandibular joint; review; epidemiology; child; adolescent.

\section{RESUMO}

Objetivo: Revisar dados de prevalência de disfunção temporomandibular (DTM) em crianças e adolescentes, verificando-se as variações metodológicas apresentadas.

Fontes de dados: Pesquisa de artigos (exceto artigos de revisão e relatos de caso) publicados de 1990 a 2012, nas bases de dados Medline, PubMed, Lilacs e BBO. Os descritores foram "síndrome da articulação temporomandibular", "síndrome da disfunção da articulação temporomandibular", "transtornos da articulação temporomandibular", "estudos de prevalência" e "estudos de corte transversal"; utilizaram-se as palavras "disfunction", "disorder", "temporomandibular", "children", "adolescents", "prevalence", "frequency" and "transversal".

Síntese dos dados: Selecionaram-se 17 estudos e a frequência de DTM variou de 16 a 68\%. Quanto aos critérios metodológicos, apenas três (18\%) estudos relataram o cálculo de poder amostral, três $(18 \%)$ explicitaram o processo de seleção da amostra, utilizando-se a técnica de seleção estratificada, e nove (53\%) realizaram calibração dos examinadores.
Endereço para correspondência:

Marina Fernandes de Sena

Avenida do Café, s/n - Monte Alegre

CEP 14040-904 - Ribeirão Preto/SP

E-mail: marinafsena@yahoo.com.br

Conflito de interesse: nada a declarar

Recebido em: 18/10/2012

Aprovado em: 18/2/2013 
Os critérios diagnósticos usados nos estudos incluídos foram: índice de Helkimo ( $\mathrm{n}=2 ; 12 \%)$, Research Diagnostic Criteria for Temporomandibular Disorders (RDC/TMD) $(\mathrm{n}=4 ; 24 \%)$, índice craniomandibular $(\mathrm{n}=1 ; 6 \%)$, protocolos de exames clínicos $(\mathrm{n}=10 ; 59 \%)$ e questionários anamnésicos $(\mathrm{n}=6 ; 35 \%)$.

Conclusões: Os relatos da prevalência de DTM em crianças e adolescentes variam amplamente na literatura. São necessárias metodologias adequadas e padronizadas para identificar, com maior validade, a presença de DTM nessa população, o que permitiria uma melhor compreensão dos aspectos patológicos e das medidas preventivas e terapêuticas mais eficazes.

Palavras-chave: articulação temporomandibular; revisão; epidemiologia; criança; adolescente.

\section{RESUMEN}

Objetivo: Revisar datos de prevalencia de disfunción témporomandibular (DTM) en niños y adolescentes, verificándose las variaciones metodológicas presentadas.

Fuentes de datos: Investigar artículos (excepto artículos de revisión y relato de caso) publicados de 1990 a 2012, en las bases de datos Medline, PubMed, Lilacs y BBO. Los descriptores de asunto fueron «síndrome de la articulación témporomandibular», «síndrome de la disfunción de la articulación témporomandibular», «trastornos de la articulación témporomandibular», «estudios de prevalencia» $\mathrm{y}$ «estudios de corte transversal»; se utilizaron las palabras «disfunction», «disorder», «temporomandibular», «children», «adolescents», «prevalence», «frequency»y «transversal».

Síntesis de los datos: Se seleccionaron 17 estudios y la frecuencia de DTM varió de 16 a 68\%. Respecto a los criterios metodológicos, solamente tres $(17,6 \%)$ estudios relataron el cálculo de poder muestral, tres $(17,6 \%)$ explicitaron el proceso de selección de la muestra, utilizándose la técnica de selección estratificada, y nueve $(52,9 \%)$ realizaron calibración de los examinadores. Los criterios diagnósticos usados en los estudios fueron: índice de Helkimo $(\mathrm{n}=2 ; 11,7 \%)$, Research Diagnostic Criteria for Temporomandibular Disorders $(\mathrm{RCD} / \mathrm{TDM})(\mathrm{n}=4 ; 23,5 \%)$, índice craneomandibular $(\mathrm{n}=10$; $58,8 \%)$ y cuestionarios anamnésicos $(n=6 ; 35,2 \%)$.

Conclusiones: Los relatos de la prevalencia de DTM en niños y adolescentes varían ampliamente en la literatura. Son necesarias metodologías adecuadas y estandarizadas para identificar, con mayor validez, la presencia de DTM en esa población, lo que permite una mejor comprensión de los aspectos patológicos para acercarse a medidas preventivas y terapéuticas más eficaces.

Palabras clave: articulación témporomandibular; revisión; epidemiología; niño; adolescente.

\section{Introduction}

The term temporomandibular disorders (TMD), according to the American Dental Association Americana (ADA), refers to a group of disorders characterized by temporomandibular joint (TMJ) pain in the periauricular area or in the muscles of mastication, in addition to TMJ sounds during mandibular function, and deviation or restriction of mandibular movements ${ }^{(1)}$.

Its multifactorial etiology is related to a heterogeneous group of functional, structural and psychological factors, which makes it difficult to identify the association between a single etiologic factor and signs and symptoms of $\mathrm{TMD}^{(2)}$. It is not clear whether these factors are considered predisposing or just coincident factors ${ }^{(3)}$.

TMD is a condition that more frequently affects adults ${ }^{(4)}$. However, signs and symptoms of TMD are observed in nearly $16^{(5)}$ to $68 \%{ }^{(6)}$ of children. The variability in its prevalence may result from the different types and qualities of analysis methods ${ }^{(7)}$.

Among the instruments for assessing TMD, there are questionnaires, clinical assessment, and imaging tests (x-ray, computed tomography and magnetic resonance imaging), used according to their applicability and to user's purposes $^{(8-10)}$.

Although some adjustments are needed due to the presence of biological variations (growth and development patterns of the masticatory system) and variations in the level of cognitive skills (understanding and ability to deal with different situations) that occur with age ${ }^{(11)}$, the methods applied to identify TMD in epidemiological studies with children are usually the same as those used in adults.

The controversy in the interpretation of signs and symptoms of TMD in children arises from the understanding of these disorders either as a variation within the normal pattern, as pre-clinical features, or as manifestations of a disease state ${ }^{(10)}$.

Thus, the prevalence of TMD in children and adolescents was assessed through a critical literature review, analyzing diagnostic criteria and methodological instruments used in the studies. 


\section{Method}

Research conducted in Medline, PubMed, Lilacs and BBO databases. The search strategy consisted of searching for the descriptors "temporomandibular joint syndrome", "temporomandibular joint dysfunction syndrome", "temporomandibular joint disorders", "prevalence studies", "cross-sectional studies", in addition to the words "dysfunction”, "disorder", "temporomandibular", "children”, "adolescents", "prevalence", "frequency" and "transversal". Search was limited to English, Spanish and Portuguese languages, considering the period from 1990 to 2012.

Articles were selected and analyzed by two independent evaluators. Initially, abstracts were selected on the basis of the abovementioned criteria. However, abstracts that did not provide enough information to make a final decision were taken up again as a complete text and evaluated according to the final selection criteria. In case of divergence, final decision was made by discussing in selection stages.

Durante the analysis process, the checklist developed by the Strengthening the reporting of observational studies in epidemiology (Strobe) initiative was used to assess the methodological quality of observational studies ${ }^{(12)}$.

The review included cross-sectional and longitudinal studies, as well as epidemiological investigations about signs and symptoms of TMD in childhood and/or adolescence. We excluded literature reviews, case reports, studies whose series comprised only adults, and studies whose sample consisted of individuals with a history of orthodontic treatment, craniofacial anomalies, degenerative disease, or TMJ trauma.

\section{Results}

A total of 383 potentially relevant citations were found in Pubmed and Medline bases. From these citations, $32 \mathrm{ab}-$ stracts were initially selected and their texts were analyzed in full. Finally, 17 articles were considered appropriate for this review, since they met the previously established inclusion criteria. Fifteen studies were found in Lilacs and five in $\mathrm{BBO}$, but none of them were selected because they did not meet the study criteria.

Regarding the methodological design, only three articles $(18 \%)^{(13-15)}$ reported sample size determination; three of them $(18 \%)$ clearly described the sampling strategy ${ }^{(2,14,16)}$, using a stratified selection technique; nine studies $(53 \%)^{(2,5,13-19)}$ carried out the calibration of the examiners.

As for the diagnostic method, two studies $(12 \%)^{(5,20)}$ used the Helkimo index; four of them $(24 \%)^{(13,15,19,21)}$, the Research
Diagnostic Criteria for Temporomandibular Disorders (RDC/TMD); one of them $(5.8 \%)^{(17)}$, the craniomandibular index; ten of them $(59 \%)^{(2,5,6,14,16,18,22-25)}$, clinical protocols; and six of them $(35 \%)^{(6,14,16,18,25,26)}$, anamnestic questionnaires (Chart 1).

The percentages of TMD varied from $16^{(5)}$ to $68 \%{ }^{(6)}$. Only two studies ${ }^{(5,26)}$ classified TMD according to its severity.

Of the 14 studies that assessed the variable sex, eight observed higher frequency of TMD in females ${ }^{(2,5,13,16,21-23,25)}$ and $\operatorname{six}^{(14,15,17-19,24)}$ did not find any difference (Chart 2).

With regard to the behavior of TMD with variation in age, of the seven studies reporting results for this variable, four of them ${ }^{(13,21,23,24)}$ detected an increase in the prevalence of TMD with advancing age and only one ${ }^{(20)}$ observed an opposite finding (Chart 2).

Regarding signs and symptoms, studies reported prevalences varying from $3^{(2)}$ to $53 \%{ }^{(23)}$ for TMJ tenderness, from $0.5^{(16)}$ to $81 \%^{(23)}$ for muscle tenderness, from $8^{(21)}$ to $48 \%{ }^{(6)}$ for joint sounds, from $2^{(2)}$ to $63 \%{ }^{(15)}$ for restricted mouth opening, and from $3^{(14)}$ to $20 \%{ }^{(21)}$ for the presence of deviations of the mandible (Chart 2).

\section{Discussion}

TMD is a condition that should be better evaluated in the population, because, if diagnosed late, it may progress to a state of irreversible destruction of the intracapsular structures of the $\mathrm{TMJ}^{(27)}$ and cause abnormal craniofacial growth, as well as TMJ-related pain or mandibular dysfunction in adulthood ${ }^{(28)}$.

Epidemiological studies in children and adolescents are essential for the investigation of signs and symptoms of TMD during childhood, a period of transition from deciduous to permanent dentition, which corresponds to the growth and development of the craniofacial complex, when there is a number of adaptive physiological changes in $\mathrm{TMJs}^{(29)}$. In this phase, most observed anomalies may be temporary, as a reflection of growth and joint remodeling ${ }^{(30)}$.

The prevalence of TMD is not well known yet, with a frequency ranging from $16.3^{(18)}$ to $68 \%{ }^{(6)}$ in the studies evaluated in this review. Such variation may result from the different evaluation methods used ${ }^{(11)}$, as well as from the lack of agreement in defining the diagnosis of temporomandibular dysfunctions in youth ${ }^{(21)}$.

In addition, other contributing factors for this variation are the variability in the frequency of sample differences related to heterogeneous age groups, the sample size, the setting of sample selection (schools, child health care centers, 


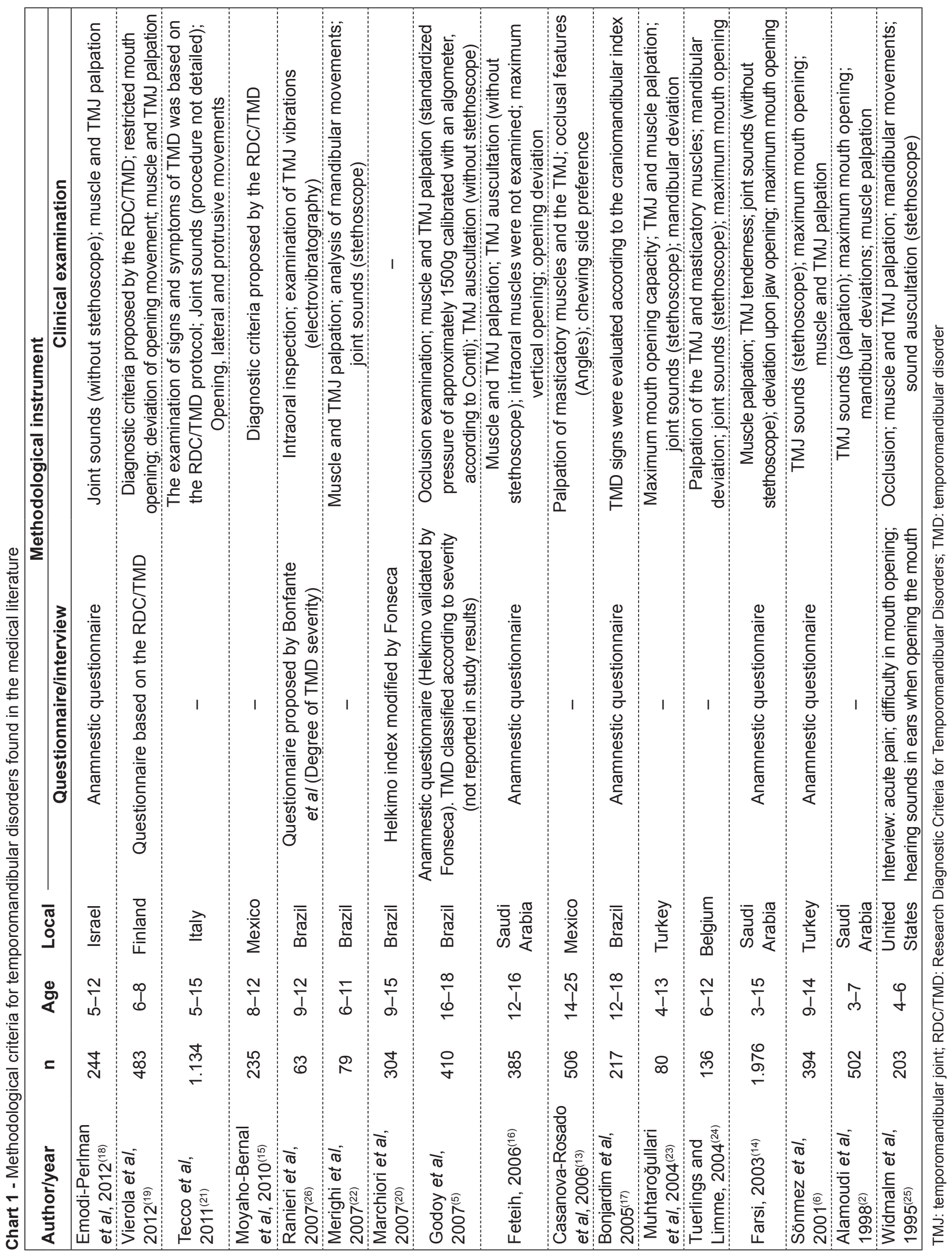




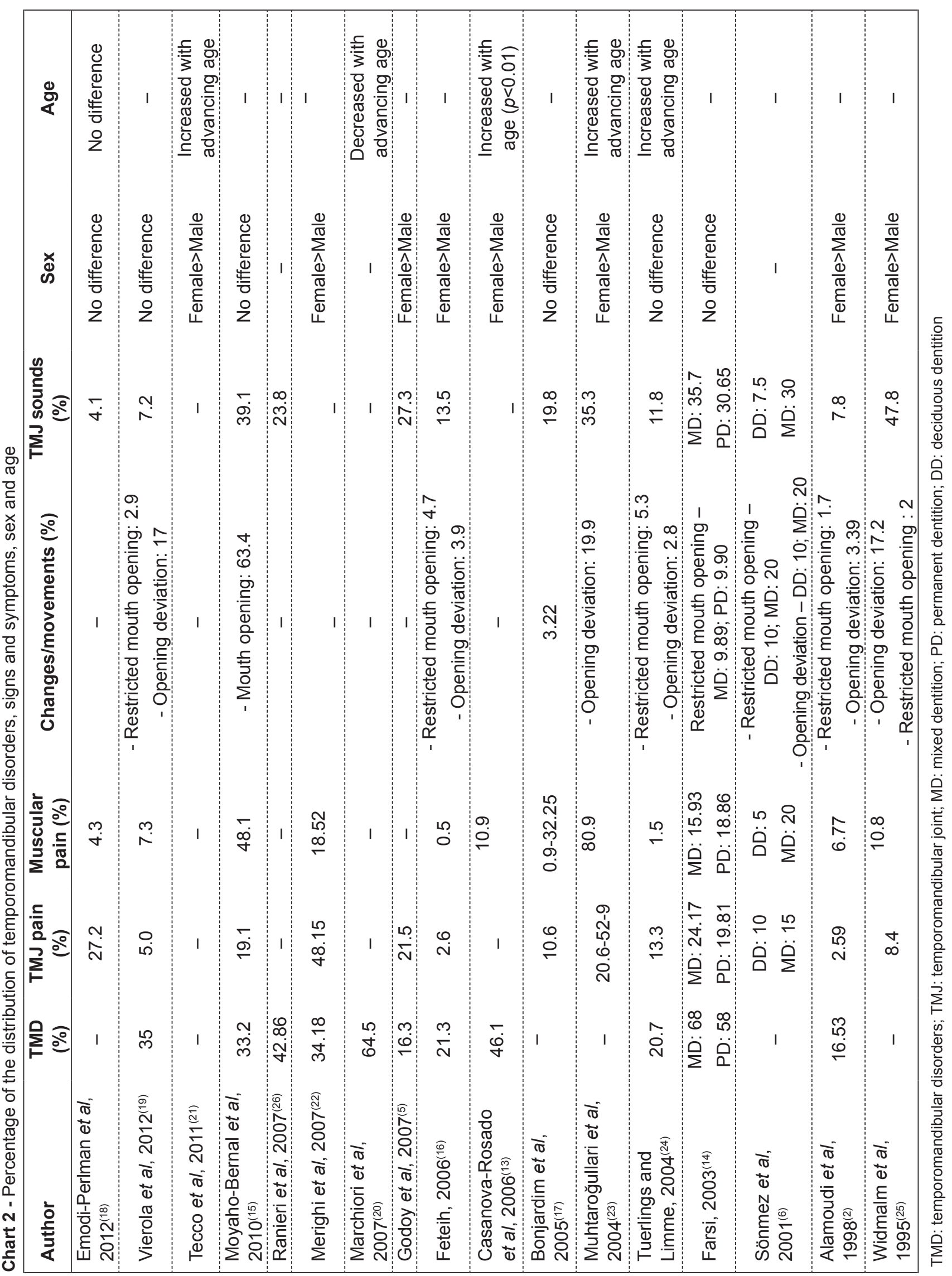


odontological clinics), and the different examination methods. In prevalence studies, it is necessary to detail sample calculation, selection and design, in order for the results to be reliable and representative ${ }^{(12)}$.

In this sense, the analysis of the studies revealed faults, such as the lack of sample size calculation. Most samples were selected by convenience sampling and only three studies reported the sample stratification process ${ }^{(2,14,16)}$. Another factor possibly related to the variability in the results for TMD prevalence is the clinical criteria adopted in the studies to investigate signs and symptoms of TMD, which were generally based on clinical protocols and self-report questionnaires.

Questionnaires are applied to draw population profiles in epidemiological studies, with functional questionnaires being the most appropriate to estimate the possible impact of TMD on daily activities. Indices are tools designed to organize the evaluation of signs and symptoms by assigning them scores ${ }^{(8)}$. In this systematic literature review, it was observed that the RDC/TMD, the Helkimo index, and the craniomandibular index, all of them related to the classification and diagnosis of $\mathrm{TMD}^{(9)}$, were used in few studies, although they may more objectively represent the significance of the disease.

Most criteria for the evaluation and diagnosis of TDM considered by the studies ${ }^{(2,5,6,14,16,18,22-25)}$ were based on clinical protocols, with no reproducible items nor a measurable and reproducible classification into diagnostic subgroups, with great variety in results, depending on the criteria used in the study and on the data collection method. A child's behavior and reactions in a clinical situation may differ from those of an adult, making interpretation of the clinical examination and interview less reliable and less valid ${ }^{(31)}$. Thus, in addition to using standardized methods of clinical examination and questionnaires validated in studies on TMD, they should be adapted to children's functional and psychological characteristics in order to obtain a reliable diagnosis.

Although there are no studies truly establishing the differences between genders, a higher frequency of signs and symptoms is observed in females ${ }^{(2,5,13,16,21-25)}$. This fact may be related to neuropsychological factors - women seem to have a lower pain threshold ${ }^{(32)}$ - and to the higher frequency of psychosomatic diseases ${ }^{(33)}$, with this gender being more vulnerable to stress ${ }^{(34)}$ and to physiological factors, such as hormonal changes. In this sense, it is worth stressing that there is a higher frequency of TMD in puberty and a reduction in prevalence rates after menopause, suggesting that female hormones have an important role in the etiology of the disorder ${ }^{(35)}$. Additionally, structural factors may also be involved, which leads us to speculate that there are differences in TMJ the components between men and women ${ }^{(36)}$. Studies that did not observe differences between genders ${ }^{(6,14,17-19,21)}$ may be explained by the fact that their samples consisted of younger individuals, which had not yet been affected by the effects of puberty ${ }^{(37)}$.

The analysis of the behavior of TMD with regard to age is very important to determine preventive treatments. In this sense, considering the different age groups, studies $^{(6,13,14,21,23,24)}$ observed a higher percentage of signs and symptoms of TMD with advancing age, as well as in the mixed dentition stage. These findings may be explained by the longer duration of muscle tension in more advanced ages, causing intracapsular changes, which suggests that muscle disorders may precede joint problems ${ }^{(38)}$. It is also believed that the higher frequency of occlusal interference and instability in the stages of mixed and permanent dentition contributes to $\mathrm{TMD}^{(39)}$. Additionally, younger individuals show a remarkable ability of adaptation of the masticatory system and of orofacial muscles, thus minimizing TMD symptoms ${ }^{(30)}$.

Muscle action has a primary role in the physiology of the orofacial complex, since changes in muscle strength may reflect in the function of the $\mathrm{TMJ}^{(28)}$. Muscle tenderness was detected by digital palpation ${ }^{(6,14,16,23-25)}$, which may be or not assisted by a placebo test to distinguish between feeling pressure and pain ${ }^{(24)}$. Muscle tenderness reported in the studies ranged from $0.5^{(10)}$ to $81 \%$; did not provide a detailed description of the procedure used to assess muscle tenderness ${ }^{(13,17)}$.

With regard to muscular symptoms, it is necessary to consider the groups and the types of muscles to be palpated. Hence, it should be emphasized that the discomfort and pain observed in response to palpation of the "lateral pterygoid area" or of intraoral muscles may be caused by other structures ${ }^{(40)}$. Additionally, palpation may cause pain in normal subjects and thus lead to false-positive results ${ }^{(41)}$.

As for TMJ tenderness, like in the examination of muscles, differences in palpation and pressure techniques may lead to little reliable results ${ }^{(17)}$. As a way of minimizing biases during examination, studies attempted to use a standardized pressure of approximately $1500 \mathrm{~g}$, calibrated with an algometer ${ }^{(5)}$.

The thee cardinal points of TMD are: orofacial pain, joint sounds, and restricted mandibular function ${ }^{(42)}$, all of which may be self-limited. One of the main clinical signs 
of dysfunctional problems of the masticatory system is the limited range of mandibular movements, which may occur both in mouth opening and in lateral and protrusive movements, or as a combination of both ${ }^{(43)}$.

The studies analyzed in this review showed a variation in the percentage of restricted mouth opening from $2^{(2)}$ to $63 \%{ }^{(15)}$. This condition was evaluated by clinically measuring the distance between the incisal border of maxillary and mandibular central incisors ${ }^{(2,6,14,16,23,25)}$ and by subjective reports in questionnaires or interviews $s^{(6,17,23,25)}$. The oscillation in the results is caused by the differences in the minimum distance established to characterize restricted mouth opening, which ranged from $30^{(6,23)}$ to $40 \mathrm{~mm}^{(16)}$. During the measuring process, the participant can make the movement of maximum mount opening twice, in order to obtain the average $^{(16)}$, or maximum opening may be measured twice and the highest value was recorded ${ }^{(14)}$. Along with the differences in the measurement of maximum mouth opening, it is possible to observe the lack of a detailed description of the measurements ${ }^{(17,24)}$ and the lack of calibration ${ }^{(6,23,25)}$.

In terms of mandibular movements, the most remarkable symptom is deviation of the mandible during opening, which ranged from $2^{(2)}$ to $20 \%{ }^{(23)}$ and was defined as the displacement of the mandible in at least $2 \mathrm{~mm}$ to the right or the left of a middle line when the mandible had reached half of its vertical opening ${ }^{(14,16,23-25)}$.

Joint sounds may be caused by anterior disc displacements of the TMJ, structural changes in the surface of the joint and hypermobility of the condyle-disc complex, in addition to degenerative processes that cause crepitations ${ }^{(44)}$. In children, sounds result from changes in TMJ contour with age, thus representing a normal finding ${ }^{(28)}$. Hence, it may not possible to ascertain whether these noises will manifest later as pathological symptoms ${ }^{(45)}$. So, in the analysis of the studies, we observed a frequency of joint sounds from $12^{(16)}$ to $48 \%{ }^{(6)}$, representing one of the most common clinical signs. The criteria and methods used to record joint sounds differ between the studies, resulting in fluctuations in their results. Thus, the factors that probably contribute to this variability are the fluctuations in the age groups included in the studies - with a possible increase in the report of signs and symptoms ${ }^{(20)}$ - and the measurement method, such as the use of stethoscope ${ }^{(6,23-25)}$, which may lead to great discrepancies in the values for joint sounds ${ }^{(6)}$, or the use of palpation and auscultation ${ }^{(5,14,16)}$. Thus, it is important to emphasize the difficulty in calibrating examiners, since the sounds do not occur with the same intensity and characteristics during the repetition of the movements throughout the time ${ }^{(25)}$. As a solution for these obstacles, it is possible to perform a simultaneous electronic analysis of the records of TMJ sounds, mandibular movements and muscle activity, as a complement to auscultation ${ }^{(46)}$.

Thus, the importance of TMJ examinations in the overall clinical assessment of the pediatric patient should not be overlooked. Identifying TMD early in life allows the clinician to follow up the patient and intervene at the appropriate time to avoid future problems in the stomatognathic system.

\section{Final comments}

The studies analyzed in this review indicated that there is variability in the results for TDM prevalence in children and adolescents, and that it is necessary to carry out additional investigations with an appropriate and standardized method designed to identify the presence of TMD with greater validity in this population. This allows a better understanding of the pathological aspects, in order to use effective preventive and therapeutic procedures.

It is worth pointing out the higher percentage of signs and symptoms of TMD with advancing age, as well as in the mixed dentition stage, and the importance of the correct diagnosis to avoid the progression of this condition.

\section{References}

1. Laskin DM. Temporomandibular disorders: a term past its time? J Am Dent Assoc 2008;139:124-8.

2. Alamoudi N, Farsi N, Salako NO, Feteih R. Temporomandibular disorders among school children. J Clin Pediatr Dent 1998;22:323-8.

3. Soviero VM, Gama FV, Castro LA, Bastos EP, Souza IP. Disfunção da articulação têmporo-mandibular em crianças: revisão de literatura. JBC J Bras Odontol Clín 1997;1:13-6.

4. Guarda-Nardini L, Piccotti F, Mogno G, Favero L, Manfredini D. Age-related differences in temporomandibular disorder diagnoses. Cranio 2012;30:103-9.
5. Godoy F, Rosenblatt A, Godoy-Bezerra J. Temporomandibular disorders and associated factors in Brazilian teenagers: a cross-sectional study. Int J Prosthodont 2007;20:599-604.

6. Sönmez H, Sari S, Oksak Oray G, Camdeviren H. Prevalence of temporomandibular dysfunction in Turkish children with mixed and permanent dentition. J Oral Rehabil 2001;28:280-5.

7. De Bont LG, Dijkgraaf LC, Stegenga B. Epidemiology and natural progression of articular temporomandibular disorders. Oral Surg Oral Med Oral Pathol Oral Radiol Endod 1997;83:72-6. 
8. Chaves TC, Oliveira AS, Grossi DB. Main instruments for assessing temporomandibular disorders, part I: índices and questionnaires; a contribution to clinicians and researchers. Fisioter Pesq 2008;15:92-100.

9. Chaves TC, Oliveira AS, Grossi DB. Main instruments for assessing temporomandibular disorders, part II: diagnostic criteria; a contribution to clinicians and researchers. Fisioter Pesq 2008;15:101-6.

10. American Academy on Pediatric Dentistry Clinical Affairs Committeetemporomandibular Joint Problems in Children Subcommittee; American Academy on Pediatric Dentistry Council on Clinical Affairs. Guideline on acquired temporomandibular disorders in infants, children, and adolescents. Pediatr Dent 2008-2009;30 (Suppl 7):202-4.

11. Ross DM, Ross SA. The importance of type of question, psychological climate and subject set in interviewing children about pain. Pain 1984;19:71-9.

12. STROBE [homepage on the Internet]. STROBE checklist for cohort, casecontrol, and cross-sectional studies [cited 2012 Jul 30]. Available from: http:// www.strobe-statement.org/index.php?id=available-checklists

13. Casanova-Rosado JF, Medina-Solís CE, Vallejos-Sánchez AA, CasanovaRosado AJ, Hernández-Prado B, Avila-Burgos L. Prevalence and associated factors for temporomandibular disorders in a group of Mexican adolescents and youth adults. Clin Oral Investig 2006;10:42-9.

14. Farsi NM. Symptoms and signs of temporomandibular disorders and oral parafunctions among Saudi children. J Oral Rehabil 2003;30:1200-8.

15. Moyaho-Bernal A, Lara-Muñoz Mdel C, Espinosa-De Santillana I, Etchegoyen G. Prevalence of signs and symptoms of temporomandibular disorders in children in the state of Puebla, Mexico, evaluated with the research diagnostic criteria for temporomandibular disorders (RDC/TMD). Acta Odontol Latinoam 2010;23:228-33.

16. Feteih RM. Signs and symptoms of temporomandibular disorders and oral parafunctions in urban Saudi Arabian adolescents: a research report. Head Face Med 2006;2:25.

17. Bonjardim LR, Gavião MB, Pereira LJ, Castelo PM, Garcia RC. Signs and symptoms of temporomandibular disorders in adolescents. Braz Oral Res 2005; 19:93-8.

18. Emodi-Perlman A, Eli I, Friedman-Rubin P, Goldsmith C, Reiter S, Winocur E. Bruxism, oral parafunctions, anamnestic and clinical findings of temporomandibular disorders in children. J Oral Rehabil 2012;39:126-35.

19. Vierola A, Suominen AL, Ikavalko T, Lintu N, Lindi V, Lakka HM et al. Clinical signs of temporomandibular disorders and various pain conditions among children 6 to 8 years of age: the PANIC study. J Orofac Pain 2012; 26:17-25.

20. Marchiori AV, Garcia AR, Zuim PR, Fernandes AU, Cunha LD. Prevalence of signs and symptoms of the temporomandibular dysfunction and anxiety in a population of Brazilian students coming from a municipal school in Jaboticabal, state of São Paulo. RGO (Porto Alegre) 2007;55:257-62.

21. Tecco S, Crincoli V, Di Bisceglie B, Saccucci M, Macrí M, Polimeni Aet al. Signs and symptoms of temporomandibular joint disorders in Caucasian children and adolescents. Cranio 2011;29:71-9.

22. Merighi LB, Silva MM, Ferreira AT, Genaro KF, Berretin-Felix G. Occurrence of temporomandibular disorder (TMD) and its relationship with harmful oral habits in children from Monte Negro - RO. Rev CEFAC 2007;9:497-503.

23. Muhtaroğullari M, Demirel F, Saygili G. Temporomandibular disorders in Turkish children with mixed and primary dentition: prevalence of signs and symptoms. Turk J Pediatr 2004;46:159-63.
24. Tuerlings $\mathrm{V}$, Limme $M$. The prevalence of temporomandibular joint dysfunction in the mixed dentition. Eur J Orthod 2004;26:311-20.

25. Widmalm SE, Christiansen RL, Gunn SM, Hawley LM. Prevalence of signs and symptoms of craniomandibular disorders and orofacial parafunction in 4-6-yearold African-American and Caucasian children. J Oral Rehabil 1995;22:87-93.

26. Ranieri RF, Garcia AR, Junqueira JM, Vedovello Filho M. Evaluation of temporomandibular disorders in children. RGO (Porto Alegre) 2007;55:229-37.

27. Farrar WB, McCarty WL. A clinical outline of temporomandibular joint diagnosis and treatment. Montgomery: Normandie Study Group for TMJ Dysfunction; 1983.

28. Kritsineli M, Shim YS. Malocclusion, body posture, and temporomandibular disorders in children with primary and mixed dentition. J Clin Pediatr Dent 1992;16:86-93.

29. Pahkala R, Laine T. Variation in function of the masticatory system in 1008 rural children. J Clin Pediatr Dent 1991;16:25-30.

30. Morawa AP, Loos PJ, Easton JW. Temporomandibular joint dysfunction in children and adolescents: incidence, diagnosis and treatment. Quintessence Int 1985;16:771-7.

31. Wahlund K, List T, Dworkin SF. Temporomandibular disorders in children and adolescents: reliability of a questionnaire, clinical examination, and diagnosis. J Orofac Pain 1998;12:42-51.

32. Dao TT, LeResche L. Gender differences in pain. J Orofac Pain 2000;14:169-84

33. Agerberg G, Carlsson G. Functional disorders of the masticatory system. I. Distribution of symptoms according to age and sex as judged from investigation by questionnaire. Acta Odontol Scand 1972;30:597-613.

34. Heiberg A, Helöe B, Krogstad BS. The myofascial pain dysfunction: denta symptoms and psychological and muscular function. An overview. A preliminary study by team approach. Psychother Psychosom 1978;30:81-97.

35. Nekora-AzakA. Temporomandibular disorders in relation to female reproductive hormones: a literature review. J Prosthet Dent 2004;91:491-3.

36. Wänman A, Agerberg G. Mandibular dysfunction in adolescents. II. Prevalence of signs. Acta Odontol Scand 1986;44:55-62.

37. Meisler JG. Chronic pain conditions in women. J Womens Health 1999;8:313-20.

38. Juniper R. Temporomandibular joint dysfunction: a theory based upon electromyographic studies of the lateral pterygoid muscle. Br J Oral Maxillofac Surg 1984;22:1-8.

39. Malmgren O. Studies on the need and demand for orthodontic treatment Swed Dent J Suppl 1980:1-121.

40. Stratmann U, Mokrys K, Meyer U, Kleinheinz J, Joos U, Dirksen D et al. Clinical anatomy and palpability of the inferior lateral pterygoid muscle. J Prosthet Dent 2000;83:548-54.

41. Fricton JR, Schiffman EL. Reliability of a craniomandibular index. J Dent Res 1986;65:1359-64.

42. Solberg WK. Temporomandibular disorders: background and the clinical problems. Br Dent J 1986;160:157-61.

43. Szentpétery A. Clinical utility of mandibular movement ranges. J Orofac Pain 1993;7:163-8.

44. Wabeke KB, Spruijt RJ, van der Zaag J. The reliability of clinical methods for recording temporomandibular joint sounds. J Dent Res 1994;73:1157-62.

45. Bernal M, Tsamtsouris A. Signs and symptoms of temporomandibular joint dysfunction in 3 to 5 year old children. J Pedod 1986;10:127-40.

46. Widmalm SE, Williams WJ, Zheng C. Time frequency distributions of TMJ sounds. J Oral Rehabil 1991;18:403-12. 